\title{
Um ensaio sobre o desenvolvimento local desde a ativação social e a governança pública
}

\author{
An essay on local development from the social activation and the \\ public governance
Un ensayo sobre el desarrollo local desde la activación social y la gobernanza pública

\author{
Alessandra de Sant'Anna ${ }^{1}$ \\ Exzovildres Queiroz Neto ${ }^{2}$ \\ Jamur Johnas Marchi
}

Recebido em 05/02/2019; revisado e aprovado em 29/05/2019; aceito em 19/06/2019. DOI: http://dx.doi.org/10.20435/inter.v21i3.2379

\begin{abstract}
Resumo: Este ensaio propõe a reflexão sobre a governança pública e a ativação social como dimensões necessárias à promoção de desenvolvimento local. A partir da revisão da literatura, identificou-se a epistemologia da participação social e da governança pública, caracterizando-as no âmbito do Estado brasileiro e problematizando-as à luz do desenvolvimento local. Conclui-se que ativação social e governança pública são indutores do desenvolvimento local.
\end{abstract}

Palavras-chave: governança pública; ativação social; desenvolvimento local.

Abstract: This essay proposes the reflection on the public governance and the social activation as dimensions necessary to promote local development. From the literature review, we identified the epistemology of social participation and public governance, characterizing them within the scope of the Brazilian State and problematizing them in the light of local development. We conclude that social activation and public governance are inducers of local development.

Keywords: public governance; social activation; local development.

Resumen: Este ensayo propone la reflexión sobre la gobernanza pública y la activación social como dimensiones necesarias para la promoción del desarrollo local. A partir de la revisión de la literatura, se identificó la epistemología de la participación social y de la gobernanza pública, caracterizándolas en el ámbito del Estado brasileño y problematizándolas a la luz del desarrollo local. Se concluye que la activación social y la gobernanza son inductores del desarrollo local.

Palabras clave: gobernanza pública; activación social; desarrollo local.

\section{INTRODUÇÃO}

Este ensaio propõe a reflexão sobre a governança pública e a ativação social como dimensões necessárias à promoção de desenvolvimento local. O estudo tem a compreensão de que os níveis de prosperidade de um país devem ser mensurados pelos níveis de bem-estar e qualidade de vida produzida pelas suas localidades e, ainda, pela capacidade de esses efeitos positivos serem vinculados pelos demais territórios e regiões. Ao adotar como perspectiva o desenvolvimento local, considera-se que o aumento de produtividade e riqueza de uma determinada região ou localidade, adicionado à capacidade de acumular capital, resulta na sua capacidade de crescer economicamente.

O desenvolvimento local é o resultado da aplicação do crescimento econômico na localidade (BOISIER, 1989) e expressa a habilidade e competência de cada região ou território

\footnotetext{
${ }^{1}$ Instituto de Pesquisa em Planejamento Urbano e Regional, Universidade Federal do Rio de Janeiro, Rio de Janeiro, Rio de Janeiro, Brasil.

2 Universidade Federal da Integração Latino-Americana (Unila), Foz do Iguaçu, Paraná, Brasil.
} 
em criar articulações capazes de empreender esforços na construção dos arranjos necessários à promoção de desenvolvimento. Esse processo somente encontra viabilidade a partir da ativação social que se expressa na mobilização dos atores locais de diferentes segmentos e no exercício de uma governança estratégica, apta no estabelecimento das melhores pactuações necessárias à composição de um planejamento regional aderente aos anseios da população e, ao mesmo tempo, a produzir consensos capazes de garantir a legitimidade do processo de tomada de decisão.

Existem dois marcos fundamentais para analisar a governança pública e a ativação social no Brasil: a Constituição Federal, de 1988, e o Plano Diretor da Reforma do Estado, de 1995. Adicionalmente, a globalização passa a requerer um novo posicionamento dos países perante a economia. O desenvolvimento local emerge como uma resposta ao liberalismo econômico, expresso pelo retorno dos pressupostos neoclássicos e pelo aprofundamento das relações de mercado diante da mudança de paradigma no modelo de Estado e, consequentemente, da administração pública.

O texto constitucional, como destacam Bigonha e Gomes Júnior (2012), reconhece a existência de uma dimensão intersubjetiva da estrutura do direito, deixando claro que o poder emanado pelo Estado provém dos cidadãos porque se trata de um modelo democrático, em que o poder é concedido pela população por meio do voto. A necessidade de responder aos seus eleitores, àqueles que delegam poder para os seus representantes, passa a requerer um modelo de administração pública orientada pela transparência, legitimidade e efetividade nos processos, escolhas, alocação de recursos e na formulação de políticas públicas, de modo a atender as pessoas em seus territórios, uma vez que lhes cabe o controle social e o governo precisa se reportar àqueles que o elegem. Os municípios, além das demandas técnico-administrativas necessárias para a operacionalização de suas novas atribuições, representam o Estado no local, tornando-se um vetor para a ativação social na construção de redes, definição de prioridades e integração dos territórios pela via de instrumentos de cooperação, termos técnicos e consórcios. Os processos de tomada de decisão decorrem, então, da gestão dos interesses expressos por atores sociais plurais, embora iguais em direitos, e da qualidade na articulação com a estrutura burocrática do Estado, que passa por um processo de transição em função de sua reforma.

O texto do Plano Diretor da Reforma do Aparelho do Estado (BRASIL, 1995) formaliza o novo rumo dado à administração pública no país, institucionaliza a governança pública, tornando mais complexa e criativa a gestão dos interesses no território, o qual é, na análise de Raffestin (1993), um espaço de exercício de poder, em que o posicionamento dos atores sociais expressa as tessituras e malhas territoriais, os limites e as possibilidades para exercícios de poder e o posicionamento dos interesses individuais diante dos coletivos e em contraposição aos diversos segmentos de atores.

Uma vez que a governança pública é orientada para a tomada de decisão, as tensões e os conflitos presentes no território se manifestam no processo de interlocução dos atores, nos processos decisórios e no conteúdo das respostas aos problemas públicos presentes nas ações, serviços, projetos, programas, planos e políticas presentes no território. Assim, a compreensão de como a governança pública e a ativação social podem contribuir para o desenvolvimento local se torna necessária por três motivos.

O primeiro decorre do fato de que a ativação social e governança são expressões da dinâmica do território que (re)produz a vida em sociedade e que, delas, de sua qualidade, derivam as escolhas públicas capazes de gerar efeitos mais ou menos positivos sobre a promoção 
de crescimento econômico e do desenvolvimento local. O segundo se refere ao fato, apontado por Paes de Paula (2005), de que a governança pública é um movimento que emerge como caminho possível de atuação do Estado diante de uma crise que se expressa pela perda de suas capacidades estatais e implica opção por modelo estatal orientado por uma lógica gerencialista, cujas bases são: eficiência, eficácia, controle social, accountability e qualidade. Este não se sustenta sem a pactuação entre os diferentes atores sociais, o que requer sua participação. Por último, a ativação social é atributo do Estado que aponta para a sua competência na mediação de interesses políticos e das relações sociais enquanto capacidade de criar, legitimar e viabilizar a participação social nos diferentes espaços públicos (sejam eles de formulação, sejam eles de controle ou decisão), de modo a auferir a qualidade e a relevância das escolhas públicas. Assim, o Estado pode e deve usar a governança pública e a ativação social como instrumentos de integração de seus stakeholders locais e contribuir para que todos se reconheçam e tenham lugar na vida pública.

Quando se adota esse movimento entre as categorias, o que está se propondo é uma perspectiva integralizadora do território, o que, na abordagem de Sepúlveda, Echeverri e Rodriguez (2005), será fundamental para a vinculação entre os territórios, os mercados e as políticas necessárias à promoção do desenvolvimento desde o local e que se conecta com a economia nacional. Ao atuar em uma perspectiva de integração, o processo de gestão do território possibilita que sejam incorporadas novas demandas e funções que passaram a compor o conjunto de ações, serviços e políticas de modo a alcançar o desenvolvimento, que, na análise de Oliveira (2002), é o crescimento aplicado na satisfação das necessidades humanas e, por isso, demanda que a sociedade participe nos processos de gestão do território.

Por se tratar de uma análise de fenômeno social, optou-se por uma abordagem qualitativa, que considera o objeto de estudo permeado de significados e relações (CHIZZOTI, 2009; MINAYO, 2007), como se verifica no principal objetivo deste estudo. A pesquisa qualitativa é caracterizada por três fases: exploratória, trabalho de campo e análise e tratamento do material. Na fase exploratória, foi elaborado o projeto de pesquisa a partir de seis processos apontados por Deslandes (2007): escolha do tópico de pesquisa, delimitação do objeto, definição dos objetivos, construção do marco teórico conceitual, escolha do instrumental e pesquisa exploratória. O estudo teve como ponto de partida a pergunta: como a ativação social e a governança pública podem contribuir para o desenvolvimento local? A hipótese que sustenta este estudo parte da compreensão de que a ativação social e a governança pública se articulam no âmbito do Estado brasileiro pela via da democracia, constituindo-se em um dos pilares do desenvolvimento local.

Este estudo partiu do objetivo geral para os específicos, identificando os procedimentos a serem realizados, a escolha do método, caráter e a abordagem envolvida nesta pesquisa. A partir dos objetivos, identificou-se que a análise do objeto envolveria processos de pesquisa de caráter exploratório, descritivo e explicativo. Aplicou-se como método de estudo a revisão da literatura no campo das ciências sociais, políticas e da administração pública e, como processo de tratamento dos dados, a análise de conteúdo (GOMES, 2007), que passou por um processo de leitura compreensiva seguida de exploração do material e síntese interpretativa.

A discussão, neste ensaio, é desenvolvida por meio de três eixos: o primeiro se ocupa de retomar conceitualmente as categorias de participação social, enquanto principal componente da ativação social; o segundo toma como referência a governança pública no Brasil, considerando as transformações ocorridas na sociedade e sua vinculação ao território; finalmente, como se 
alinham participação social e governança no momento em que se estabelece um Estado de cunho democrático e seu aparelho é reformado. A partir da caracterização das duas categorias, participação social e governança pública, buscou-se apontar os dissensos e consensos em torno desse tema. Por último, buscou-se compreender como a combinação entre ativação social e governança é capaz de produzir desenvolvimento local, seja pela via da melhor alocação de recursos, seja pelo desenho de políticas públicas capazes de induzir o crescimento e contribuir para a condição de vida das pessoas.

\section{A PARTICIPAÇÃO SOCIAL E A GOVERNANÇA PÚBLICA NA TRAJETÓRIA DE FORMAÇÃO DO ESTADO BRASILEIRO}

Só é possível ativar a sociedade quando existe o interesse de seus membros em ocupar os espaços públicos e interagir na dinâmica social visando à construção de um bem público. As pessoas vêm ocupando o território de diferentes formas ao longo do desenvolvimento do Estado, daí a importância de distinguir a ocupação dos espaços de participação social, tomando como referência os mecanismos de viabilização da participação social na dinâmica da sociedade. Rocha (2008) problematiza a forma como ocorre a participação social no Brasil, considerando a sua inserção histórica, bem como as formas de mobilização e participação da sociedade no tecido social, as quais não implicam, necessariamente, uma prática orientada pela democracia participativa. É preciso diferenciar a participação enquanto ocupação do espaço público da participação social institucionalizada ou dotada de intencionalidade, que tem como objetivo efetivar direitos e construir o bem comum.

Figura 1 - A participação social desde o Brasil colonial até a reabertura democrática

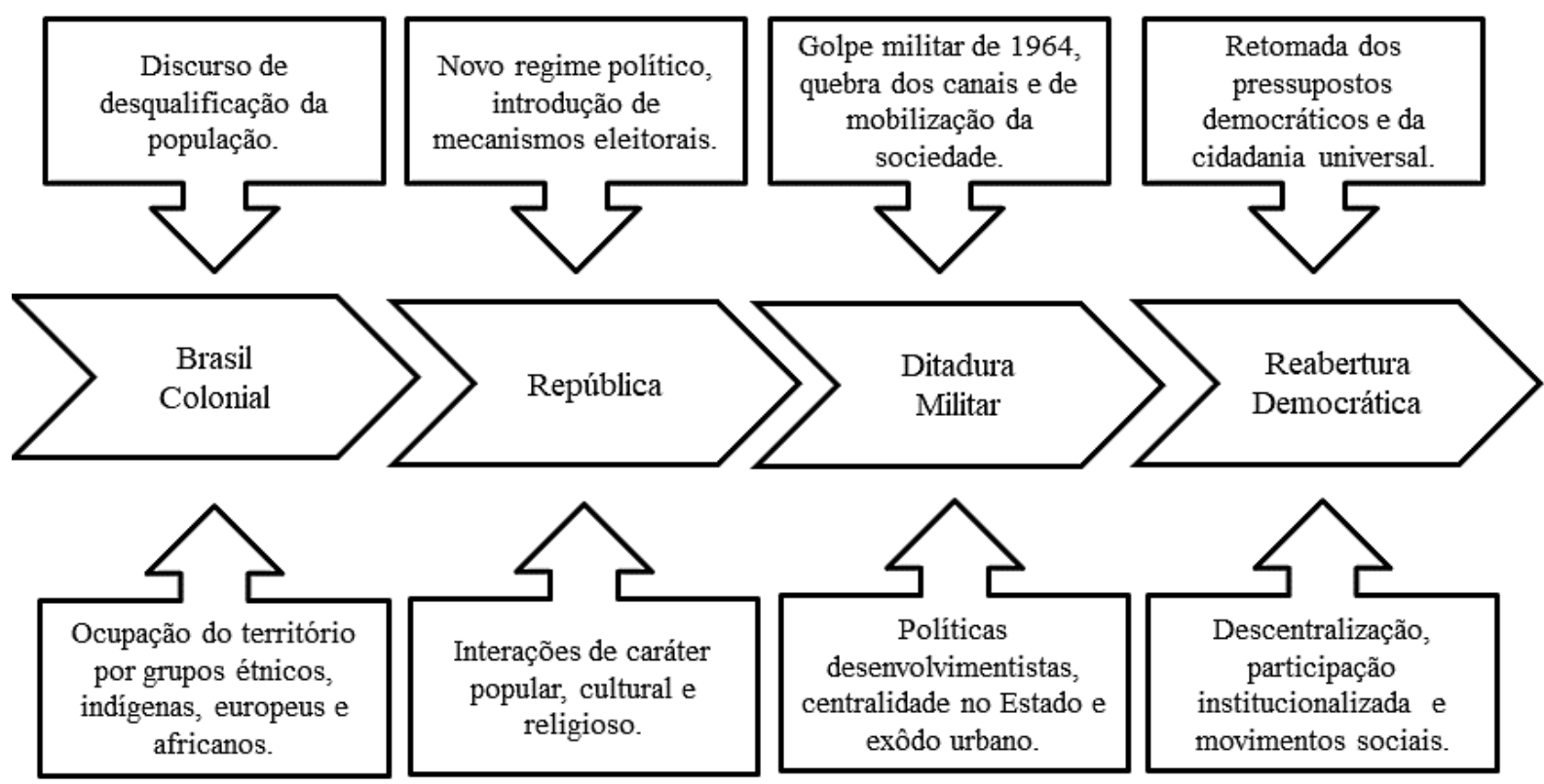

Fonte: Elaborado pelos autores a partir de Rocha (2008).

No caso brasileiro, desde a colonização é possível observar mecanismos de ocupação do tecido social. A participação social adquire contornos mais claros a partir da década de 1970, vinculada à emergência dos movimentos sociais (GOHN, 2011). Posteriormente, a sua 
institucionalização resulta da redemocratização do país e da aprovação do texto constitucional. Gohn $(2011 ; 2008)$ destaca a importância dessa forma de organização da sociedade civil no processo de institucionalização da participação social no país, uma vez que a eles cabe a publicização dos problemas e demandas da população que, de forma organizada em um espaço coletivo, de caráter cultural, social e político, passa a pressionar o poder público na oferta de melhores condições de vida e atenção às suas necessidades e direitos.

A democracia participativa resgata uma discussão que não é nova, ao abordar a relação entre público e privado no sentido dos resultados dessa participação social. Dagnino (2004a; 2004b) problematiza essa discussão destacando a necessidade de assegurar que os resultados das disputas e dos processos decisórios tenham caráter coletivo e público, no sentido de que atendam aos interesses da sociedade, e não apenas de uma parcela dela. Martins (2011) sinaliza que reduzir a participação social a um processo de mobilização intencional dos atores sociais tem um impacto significativo em termos do que é e para quem se produz, o que determina, em última instância, o conteúdo de bens, de serviços e políticos. Essas escolhas podem ocorrer em um contexto de alargamento e expansão dos bens, no sentido de produzir efeitos positivos sobre o território e contribuir para a melhora das condições de vida da população ou atender a um segmento específico, mantendo as desigualdades existentes no território que, ainda que produza riqueza, será incapaz de promover desenvolvimento.

O principal óbice para ocupação da esfera pública é a indefinição do conceito de sociedade civil no sentido de compreender quem são os atores sociais e stakeholders envolvidos em cada um dos processos. Em se tratando de esfera pública, é importante sinalizar que há um deslocamento entre esses atores a depender das questões que estão em jogo, emergência de novos atores sociais e jogos políticos que determinam o grau de aderência, participação e influência no tecido social.

Kristsch (2014) parte do entendimento de que a sociedade civil é composta por um conjunto de cidadãos politicamente organizados situados fora do Estado ou governo, reunidos em torno de um objetivo comum, o qual terá impacto sobre a legitimação do Estado. Trata-se, portanto, de uma dimensão de fiscalização e controle das ações da administração pública enquanto o que foi instituído e normatizado. Para Arato e Cohen (1994), a sociedade civil é o conjunto de todas as instituições que interagem em uma dimensão que é pública, no sentido de mundo da vida sugerido por Habermas. E o produto da articulação dos sistemas, estruturas sociais e das relações de poder que interagem no território é entendido por Queiroz Neto, Ribeiro e Vargas (2016) como um espaço em movimento, (des)construído historicamente, determinado por relações de poder decorrentes da interação entre os diferentes membros da sociedade civil. Esses autores adotam uma perspectiva bem próxima à de Arato e Cohen, ao considerar que esses atores têm "múltiplas e simultâneas funções, lugares contíguos, dispersos e lugares em rede" (QUEIROZ NETO; RIBEIRO; VARGAS, 2016, p. 38).

Assim, os jogos e inter-relações presentes no território têm visibilidade por meio de um processo que, embora contraditório, é dotado de intencionalidade, de disputas por poder e pela satisfação de interesses. Tais relações ocorrem no âmbito da democracia, compreendida por Bobbio (2000) como uma forma de governo em que o poder não está concentrado nas mãos de uma minoria, mas da maior parte da sociedade. Na abordagem de Bourdieu (1983), o poder exercido no âmbito dessas estruturas tem um caráter simbólico que se desenvolve a partir do processo de comunicação como forma de interação social. A democracia, tomada em seu caráter participativo, é, segundo Bobbio (2007), a via que garante e legitima a participação social e carrega 
consigo uma dimensão de exercício do poder em uma perspectiva de res pública, referindo-se à coisa pública, ou de principado, no sentido de restrição e de um caráter mais privado.

Resgata-se então a dimensão da representatividade na esfera pública ou mundo da vida, em uma perspectiva habermasiana. A interação entre os sistemas e estruturas resultados de processos de tomada de decisão (escolhas, ações, serviços, programas e políticas) ganha materialidade por meio do aparato de Estado. Para Habermas (1981), o Estado é a administração pública que tem como atributo a publicidade no exercício de sua tarefa de cuidar do bem comum e dos cidadãos. Quanto maior a capacidade do Estado em promover espaços para o exercício da democracia e quanto maior diversidade de representação social existir nos processos de tomada decisão, maior a sua capacidade política na geração de respostas que deem conta dos problemas e das necessidades dos territórios, que são espaços de participação e governança pública.

As questões supramencionadas que interferem nos processos de participação social perpassam também a lógica da governança pública, um movimento que surge a partir de um processo de mudança ou modernização do Estado em decorrência de cinco elementos apontados por Secchi (2009): crise fiscal do Estado; competição territorial pelos investimentos privados e mão de obra qualificada; disponibilidade de novos conhecimentos organizacionais e tecnologia; ascensão de valores pluralistas e neoliberais; e a crescente complexidade, dinâmica e diversidade das nossas sociedades.

Trata-se de um processo determinado por fatores internos e externos ao Estado, que culmina na perda das capacidades estatais tanto em sua dimensão burocrática quanto em sua dimensão política. Existem diferentes percepções de capacidades estatais. Souza e Carvalho (1999) adotam a perspectiva de que o Estado é dotado de capacidades administrativas - que se relacionam com o aumento do desempenho e a satisfação da necessidade dos cidadãos - e de capacidades institucionais - que se referem aos mecanismos de cooperação e legitimidade no âmbito governamental. O'Donnel (2015) alerta para o fato de que as capacidades estatais transcendem a dimensão burocrática do Estado e limitar tais capacidades à burocracia constitui um erro, um reducionismo. Essa perspectiva é partilhada por Souza e Carvalho (1999), que destacam a importância de também compreender e situar o Estado sob a ótica relacional.

Os fatores que levam à emergência da governança pública no Brasil se relacionam com a perda de suas capacidades estatais tanto na dimensão burocrática quanto na dimensão política, como apontam Paes de Paula (2005), Bresser-Pereira (2009; 1998) e Brasil (1995), as quais têm impactos severos na dimensão econômica, dado que o mundo atravessa uma crise e decorrência da perda de intensidade do capitalismo, tal como estava estabelecido. Paralelamente, a globalização emerge como uma nova forma de gerir o mercado por meio de sua internacionalização e acirramento da competitividade entre as economias que passam a atuar em um mercado global, em que as tendências de uma determinada economia geram efeitos para as demais. Aprofunda-se o liberalismo por meio do comércio mundial; o sistema capitalista, como característica intrínseca a sua natureza, é promotor de desigualdades, as quais são intensificadas a partir das limitações impostas ao Estado, que passa a ser coordenador regulador e interventor das relações sociais, com a finalidade de viabilizar as melhores condições para o crescimento da economia. As perdas relacionadas à capacidade política do Estado são solucionadas por meio da introdução da governança pública, entendida, inicialmente, como "a capacidade financeira e administrativa em sentido amplo de uma organização de implementar suas políticas" (BRESSERPEREIRA, 1998, p. 83). 
Em seu estudo, Leonardo Secchi (2009) aponta a existência de diferentes conceitos de governança. Para as relações internacionais, refere-se às mudanças nas relações de poder entre os Estados no contexto internacional. Para os globalizers, ela se relaciona com a construção de redes colaborativas para enfrentamento de problemas que perpassam vários países. Para os teóricos do desenvolvimento, a governança pública é uma associação de práticas democráticas com gestão, com o propósito de promover seu desenvolvimento econômico e social. O autor aponta ainda que, para os empresários e contadores, o termo governança se refere à adoção de princípios básicos, com o objetivo de contribuir para a efetividade de controle das partes interessadas e autoridades de mercado em relação a organizações privadas de capital aberto.

De forma prática, a partir de 1995, com a reforma do aparelho de Estado brasileiro, existem duas estruturas que, embora com finalidades diferentes, são complementares: a gestão pública e a governança pública. A primeira se relaciona à esfera técnica administrativa caracterizada pelos bons instrumentos burocráticos que precisam continuar para que haja governabilidade e o Estado possa cumprir o seu papel de meio de reprodução social e geração de bem comum (AZAMBUJA, 2005); e a segunda, objeto deste estudo, que se refere à esfera político-relacional, a governança pública, responsável pelo fortalecimento do seu papel institucional, construção de redes de cooperação inter e intragovernamental e pelos processos de tomada de decisão. Diferentes concepções de governança têm como ponto comum, segundo Dias e Cario (2014), o impacto nas estruturas, relacionadas ao deslocamento do poder estatal e nas instituições, que se dá pelo estabelecimento de redes de cooperação. Ambas as dimensões são importantes para se pensar o governo em qualquer esfera. Da gestão, ocorre a operacionalização, a materialização das pactuações ocorridas na governança e, ao mesmo tempo, sinalizam-se os problemas identificados no exercício de sua função técnico-administrativa. Toda instituição, no Estado gerencial, apresenta as duas dimensões.

À governança, cabe a percepção das diferentes tipologias de necessidades, a identificação e formação de redes, a mobilização e a ativação dos atores locais, de modo a estimular a sua participação nos processos, sistemas e espaços de pactuação, controle e tomada de decisão. Trata-se, portanto, de um exercício de poder dos atores locais que permeiam as estruturas sociais. Os autores sinalizam que esse deslocamento de poder pode ocorrer por três vias: downward - que estaria ligado à descentralização; upward - que se refere ao reporte do poder central a instâncias transnacionais; e outward - por meio do estabelecimento de convênios e parcerias e privatizações.

A governança pública apresenta, então, uma dimensão democrática que se expressa na forma de construção das respostas aos problemas sociais, compreendida por Dias e Cario (2014, p. 89) como uma "relação com a construção do público, pelo público e para o público". Novamente, retoma-se o pensamento de Raffestin (1993) e a análise do território a partir das relações de poder, construídas a partir de redes, malhas e tessituras, em que o deslocamento das relações ou o reposicionamento dos atores, ou as características dos atores que compõem o espaço público, determinam o conteúdo, a finalidade e a qualidade dos processos de tomada de decisão em cada localidade. A respeito da relação entre governança e redes de cooperação, "as redes são um modo de organização e a governança a capacidade ordenadora, ou, de forma mais compreensiva, um sistema de ordenação" (LIMA, 2014, p. 1233). Nesse sentido, governança pública e participação social se aproximam porque são instâncias políticas da vida social e derivam da democracia participativa enquanto atributo do Estado. 


\section{CONSENSOS E DISSENSOS EM TORNO DA ATIVAÇÃO SOCIAL E DA GOVERNANÇA PÚBLICA}

Governança pública e ativação social têm caráter relacional e político e se inscrevem no interior da democracia participativa, o que pressupõe o estabelecimento de comunicação, a qual se desenvolve em um espaço público compondo o que Habermas denomina de mundo da vida e a qual Arato e Cohen (1994) e Gutierrez e Almeida (2013) ratificam. A governança é situada, de acordo com Pires et al. (2011), como mediadora das relações entre Estado e mercado, entre os interesses locais e globais, posto que estes atuam como mecanismo de regulação e controle do território e se desenvolvem por meio dos acordos e redes estabelecidos para enfrentamento dos problemas. A participação social se dá na perspectiva de que os atores sociais têm problemas, demandas e interesses e optam por um enfrentamento desses problemas por meio da ocupação de espaços públicos. Assim, eles se mobilizam, reivindicam, pressionam e se articulam de forma organizada e coletiva em torno de um objetivo comum, visando à elaboração de respostas e ao desenvolvimento de soluções que ocorrem pela via do Estado na vida pública.

Fóruns sociais, orçamentos participativos, conselhos municipais, assembleias e plenárias, mobilizações locais de grupos de mulheres e de orientações sexuais diversificadas, movimentos étnicos, nacionalistas, culturais e religiosos, tudo isso compõem o quadro que tem sido conhecido como democracia participativa nas duas últimas décadas. (MARTINS, 2011, p. 15).

A realização de audiências públicas, as associações, as cooperativas, os conselhos consultivos, os conselhos de desenvolvimento econômico e social, as câmaras técnicas, os consórcios intermunicipais e os painéis de diagnóstico são outras formas de participação social. A democracia é um espaço de poder e nela o público adquire influência sobre o Estado e a economia, porque o poder emana dos cidadãos, porque é um meio para que sejam incorporadas nas escolhas públicas os anseios e interesses da população. Por ser um espaço de poder, é também um lugar de mudanças, as quais se consolidam nas políticas públicas enquanto instrumentos de mudança aptos à incorporação e à institucionalização de demandas.

Secchi (2015) considera que a política pública é uma orientação cuja finalidade está no enfrentamento de um problema, constituindo-se, necessariamente, por dois elementos: “intencionalidade pública e resposta a um problema público” (SECCHI, 2015, p. 2).

Considerando que política pública é o produto de complexas interações e decisões entre os atores e instituições, cujo desfecho não é determinado de antemão, depende do curso que torna a ação, e considerando a "emergência" - o fato de que novos padrões surgem de uma série de interações e múltiplas decisões que podem mudar a direção de eventos ao redor do mundo - estamos diante de cenários imprevisíveis e complexos que exigem novas soluções. (FERRAREZI; OLIVEIRA, 2013, p. 119-20).

Existe então, um componente que pode ser estratégico tanto para a participação social quanto para a governança pública. O caráter estratégico da participação parece estar em sua capacidade de produzir associações e dissociações como resultadas dos interesses que estão em jogo, um jogo político. O que mobiliza as pessoas a participarem dos espaços parece ser diferente, uma vez que o tecido social não é harmônico e naturalmente orientado ao consenso,

[...] o xadrez da organização do espaço é um jogo de múltiplas variáveis que se estabelece no território do município, são múltiplas linguagens, paisagens objetos, ações, visões de mundo, 
elementos materiais, imateriais e simbólicos. Por se tratar de um espaço racional (concepção mais ampla), o município é alvo de várias estratégias e territorializações. (QUEIROZ NETO; RIBEIRO; VARGAS, 2016, p. 38).

O caráter estratégico da governança pública está na articulação de sistemas e processos internos e/ou externos dotados de intencionalidade dentro de um processo de tomada de decisão; refere-se, portanto, à capacidade de converter em ações práticas o que foi decidido, seja pela via de leis e normas, destacadas por Siong e Chen (2007), seja pela oferta de planos, políticas, programas, projetos, serviços, extinção ou ampliação de cobertura, emprego ou não de recursos humanos, financeiros ou materiais, apontados por Pires e Gomide (2016). Nesse sentido, Dagnino (2004a; 2004b) chama atenção para cuidados que precisam ser tomados em relação a uma confluência perversa nos espaços públicos, como resultado de distorções nos processos de tomada de decisão relacionados ao uso e à qualidade desses espaços.

O risco - real - que elas percebem é que a participação da sociedade civil nas instâncias decisórias, defendidas por formas que sustentam o projeto participativo democratizante como um mecanismo de aprofundamento democrático e de redução da exclusão, possa estar servindo aos objetivos do projeto que lhe é antagônico. (DAGNINO, 2004b, p. 143-4).

A qualidade da ocupação dos espaços decisórios aponta, ainda, para relações de confiança e condições éticas necessárias à participação democrática como meios de verificação do nível de capital social de um território. "Por sua vez, essas ações, relações e associações, são a base a partir da qual se produz o capital social que repercute, em maior ou menor medida, na configuração e conformação socioeconômica dos territórios" (DURÁN; LANNOO, 2014, p. 193, tradução nossa).

Uma vez que se adentra a esfera valorativa da governança pública e da participação social, Neves et al. (2017) destacam três características da governança pública: valor centrado no bem comum; desenvolvimento de processos capazes de atender diferentes atores; e criação de um bem público. Estes valores também estão presentes na participação social, enquanto produto da cidadania, da política e da democracia, que, na análise de Zanella (2008), para além de conceitos, referem-se a valores que orientam a ocupação do tecido social.

A partir da interação entre a participação social e a governança pública, recomenda-se a adoção de quatro linhas de ação: criar espaços que possibilitem a ocupação da sociedade civil nos processos de tomada de decisão, estimular a participação por meio de um mapeamento das partes interessadas, promover articulação em prol de objetivos comuns e desenvolver redes de cooperação que permitam a capilaridade das ações, serviços e políticas públicas. Há de se destacar, ainda, a importância de atores sociais diversos, pois a pluralidade de percepções e conhecimentos em torno da compreensão de um determinado problema público possibilita a elaboração de respostas mais aptas às necessidades do território, o que contribuirá para o fortalecimento de suas forças e oportunidades, bem como para a eliminação ou mitigação de suas fraquezas e ameaças. A partir daí criam-se os meios necessários para viabilizar desenvolvimento local.

\section{ATIVAÇÃO SOCIAL E GOVERNANÇA PÚBLICA COMO VIABILIZADORAS DO DESENVOLVIMENTO LOCAL}

Em um primeiro momento, faz-se necessário conceituar o que é desenvolvimento local para, a partir dessa linha de base, analisar a contribuição da participação social e da governança pública nesse processo. Dallabrida (2011) considera que o desenvolvimento local se refere às 
mudanças empreendidas pela sociedade local na elaboração de estruturas capazes de otimizar o emprego dos recursos presentes no território, de modo a contribuir para a produção de riqueza e sua conversão em bem-estar e qualidade de vida para a população. É, portanto, derivado do entrelaçamento da governança (objeto deste estudo) e da gestão públicas instituídas no território.

A governança pública deriva da dimensão político-relacional da esfera pública, em que se situa a participação social e a qual envolve a mobilização, diagnóstico, tomada de decisão, pactuação, construção, formalização, manutenção e acompanhamento da rede. É a qualidade da governança que determina a capacidade de os serviços atenderem às necessidades locais, a incorporação de mudanças nos rumos das políticas locais, o estabelecimento de redes de cooperação e parcerias com a finalidade de suprimento das demandas da localidade/ região/ território. A esse respeito, o Observatório de Políticas Públicas para a Agricultura (OPPA, 2007, p. 6) considera que

\begin{abstract}
A abordagem da territorialização da governança busca utilizar a noção do território como locus espacial e socioeconômico privilegiado para implementar processos de descentralização das atividades governamentais e da relação entre Estado e sociedade, que tiveram um papel relevante no processo de democratização da política do Brasil a partir da metade da década de 1980.
\end{abstract}

Nessa mesma linha, Dallabrida e Becker (2003) apontam que intervenções territoriais inteligentes se apoiam em duas construções: de um novo conhecimento e de um poder político local/territorial. O que determina a qualidade dessas construções é o volume de capital social envolvido e a densidade de instituições acumuladas nesse espaço, a qual pode ser explorada por meio de redes de cooperação, que

[...] reforçam a capacidade de ação coletiva dos atores locais, estimulam a realização de alianças, fortalecem a implementação participativa das políticas públicas e favorecem a criatividade social e a efetividade do processo da política, quem sabe construindo condições institucionais para uma articulação e integração crescentes das ações, muitas vezes diversas e contraditórias, voltadas para o desenvolvimento local/territorial. (OPPA, 2007, p. 4).

Nesse sentido, é possível que se tenha uma localidade passiva - quando há pouco capital social envolvido ou quando esse capital social não é de boa qualidade - ou uma localidade ativa - quando há um maior incremento de capital social ou quando a qualidade dos atores envolvidos seja capaz de traduzir as necessidades do território, de modo que as decisões tomadas apresentem elevado grau de eficácia, eficiência e efetividade. De abordagem institucionalista, Favareto (2010) destaca o esgotamento dos mecanismos de participação social que já não atendem a realidade social, indicando a necessidade de se desenvolver outras formas de participação social, em espaços que possibilitem a maior aderência dos atores sociais e maior qualidade nos processos de tomada de decisão.

Não se trata de dizer que a gestão social das políticas públicas é um desafio superado, e sim que os desafios na gestão social das políticas públicas tornaram a agenda que hoje inspira essas formas de participação social, algo envelhecido. Em outras palavras, os instrumentos de participação social hoje são os mesmos desenhados há duas décadas. E, no entanto, já há aprendizagem com as experiências que permitiria refinar e aprimorar estes mês mos instrumentos. (FAVARETO, 2010, p. 60).

Para que as instituições sejam eficientes e que possibilitem o desenvolvimento no âmbito das localidades, é necessário que haja coerência e complementaridade (FAVARETO; SCHRODER, 
2007) entre o que foi articulado e o que foi produzido. Dessa forma, o caráter estratégico da governança na promoção do desenvolvimento local está em resguardar a coerência e a complementaridade das ações, visto que comporta as demandas, as mediações e as correções de rumo presentes nos processos de tomada de decisão do qual participaram diferentes atores sociais. Há um componente na governança que se refere à gestão do conhecimento produzido nesses processos, da mediação de interesses e da construção de mecanismos de pactuação. À medida que se conformam redes e se mobilizam os grupos e segmentos envolvidos, cada ator é atraído ou afastado segundo a natureza dos consensos que se pretende produzir.

Nesse contexto, a governança tem uma função de regulação local ou regulação do território, e a literatura apresenta dois entendimentos sobre essa perspectiva. O primeiro está presente no pensamento de Lins (2006), para quem a governança é vista como coordenadora do conjunto de regras, relações, atores sociais e arranjos institucionais presentes nos territórios. O segundo é destacado por Dallabrida (2007), que compreende a governança territorial como uma capacidade da sociedade que, por meio da organização no território, se torna partícipe do gerenciamento das questões públicas por meio da interação com os atores institucionais, econômicos e sociais. Os níveis de participação social influenciam os diferentes espaços institucionais e são determinantes para que se obtenha desenvolvimento ou não em uma determinada localidade ou território, posto que a dimensão espacial pode ser verificável, uma vez que

[...] os recortes territoriais podem ser regiões administrativas, regiões metropolitanas, áreas de abrangências de comitês de bacias hidrográficas, um município ou parte dele, um bairro ou mesmo a área de abrangência de experiências de indicação geográfica. (DALLABRIDA et al., 2016, p. 44).

Em se tratando do estabelecimento de ações, serviços e políticas públicas, é importante considerar também a existência de territórios subjetivos que se referem aos acordos e pactuações necessários para a materialização dessas ações, serviços e políticas públicas, principalmente se a gestão for híbrida.

A participação ativa dos atores/agentes regionais nos diferentes tipos de práticas institucionais voltadas ao exercício da governança territorial constitui-se no processo de concertação grupal ou corporativa para a elaboração de consensos grupais ou corporativos. Isso constitui-se numa das condições básicas para que aconteça a tão almejada meta: a região tornar-se sujeito do seu processo de desenvolvimento. (DALLABRIDA; BECKER, 2003, p. 81).

Uma fonte de convergência entre a governança pública e participação social é o processo e construção das redes de políticas, comitês e fóruns temáticos enquanto espaços onde se podem identificar problemas, avaliar a qualidade dos serviços em andamento, identificar os nós e realizar ajustes em nível local de modo a tornar as instituições e os arranjos institucionais, eficazes, eficientes e efetivos, de modo a ofertar um serviço de qualidade e dotado de transparência para os cidadãos.

A rede de política territorial é uma estratégia de coordenação de fluxos de comandos e decisões, capaz de formar uma arena política e de Ihe conferir visibilidade, requalificando um dado território. Esse tipo de rede se forma a partir da dinâmica territorial, retroagindo com esta última. As redes políticas configuram e reforçam circuitos territoriais de poder, expressam tais circuitos, um movimento de recomposição do território. (LIMA apud LIMA, 2014, p. 1.234). 
Outro elemento que materializa a confluência entre a participação social e a governança pública são os consórcios e as associações interfederativas, uma forma dé prover serviços que antecede a Constituição Federal de 1988 e o processo de descentralização. Dallabrida (2010) considera os consórcios intermunicipais de desenvolvimento como institucionalidades de caráter tático e operacional na provisão de desenvolvimento local por meio de estrutura de governanças territoriais. Cançado, Tavares e Dallabrida (2013) destacam as abordagens multiníveis da governança territorial que possibilitam e potencializam a captação de recursos por meio da interação entre atores como empresas, visando ao estabelecimento de matrizes e filiais na localidade. Por último, Fuini (2013) destaca os Arranjos Produtivos Locais (APLs) e os circuitos turísticos como importantes instrumentos de desenvolvimento derivados da governança do território e, consequentemente, da participação social, dado que comportam vínculos cooperativos e interinstitucionais. Isso posto, é possível estabelecer uma síntese da ativação e da governança pública como indutores do desenvolvimento local (Quadro 1) considerando as seguintes categorias: caráter; valores; contexto; mecanismos de interação; ambiente; componente estratégico; riscos; e articulação em nível local.

Quadro 1 - Ativação social e da governança enquanto indutoras de desenvolvimento local

\begin{tabular}{|l|l|l|}
\hline \multicolumn{1}{|c|}{ Categorias } & \multicolumn{1}{|c|}{ Participação social } & \multicolumn{1}{c|}{ Governança pública } \\
\hline Caráter & Político-relacional. & Político-relacional. \\
\hline Valores & $\begin{array}{l}\text { Bem comum, envolve diferentes atores } \\
\text { e criação de um bem público. }\end{array}$ & $\begin{array}{l}\text { Bem comum, envolve diferentes } \\
\text { atores e a criação de um bem } \\
\text { público. }\end{array}$ \\
\hline Contexto & Democracia participativa. & Democracia participativa. \\
\hline $\begin{array}{l}\text { Mecanismos } \\
\text { de interação }\end{array}$ & Comunicação. & Comunicação. \\
\hline Ambiente & Mundo da vida. & Mundo da vida. \\
\hline $\begin{array}{l}\text { Componente } \\
\text { estratégico }\end{array}$ & $\begin{array}{l}\text { Capacidade de produzir associações e } \\
\text { dissociações. }\end{array}$ & $\begin{array}{l}\text { Articulação de sistemas e } \\
\text { processos. }\end{array}$ \\
\hline Riscos & $\begin{array}{l}\text { Confluência perversa nos espaços } \\
\text { públicos, prevalência de interesses } \\
\text { privados sobre os coletivos. A baixa } \\
\text { participação ou restrição da participação } \\
\text { tem efeitos sobre a legitimidade e } \\
\text { transparência das escolhas públicas. }\end{array}$ & $\begin{array}{l}\text { Baixa qualidade do processo de } \\
\text { tomada de decisão, na construção } \\
\text { do planejamento regional e nos } \\
\text { efeitos das políticas públicas, } \\
\text { sobretudo as setoriais. }\end{array}$ \\
\hline $\begin{array}{l}\text { Articulação no } \\
\text { âmbito local }\end{array}$ & $\begin{array}{l}\text { Possibilitar a ocupação da sociedade civil nos processos de tomada de decisão, } \\
\text { estimular a participação por meio de um mapeamento das partes interessadas, } \\
\text { promover articulação em prol de objetivos comuns e desenvolver redes } \\
\text { de cooperação que permitam a capilaridade das ações, serviços e políticas } \\
\text { públicas. }\end{array}$ \\
\hline
\end{tabular}

Fonte: Elaborado pelos autores.

Ao término da análise, verificou-se que desenvolvimento local é resultado da soma entre governança e gestão pública, decorrente de construção estruturalista das relações, serviços, políticas, poderes e vida cotidiana. Quanto maiores forem os níveis de democracia, expressos pela qualidade da participação social, maiores os níveis de eficácia, eficiência e efetividade das ações tomadas. Estas adquirem diferentes efeitos sobre a dinâmica do território e sobre a qualidade de vida das pessoas em função das escolhas feitas no âmbito da esfera pública, determinando, assim, os níveis de desenvolvimento local. 


\section{CONSIDERAÇÕES FINAIS}

O estudo verificou a existência de diferentes formas de participação social e governança pública na promoção de desenvolvimento local no âmbito de atuação do Estado brasileiro. Do ponto de vista de quem participa, há de se considerar que a produção de desenvolvimento no contexto de um território envolve atores sociais de diferentes naturezas e que, de fato, eles se reúnem a partir do objetivo que se pretende alcançar. Governança pública e ativação social são dimensões de um Estado democrático que se encontram na mobilização, diagnóstico, pactuação, tomada de decisão, planejamento regional, formulação e implementação de políticas públicas, controle social, construção e manutenção dos processos necessários para a produção de desenvolvimento local expresso no produto dessas duas dimensões, quais sejam: alinhamento de interesses, ações, serviços, avaliação das políticas públicas e a escolha quanto à sua extinção, mudança ou continuidade na construção de rede, estabelecimento de parcerias e outros arranjos institucionais que dinamizem o territórios.

A literatura destaca a necessidade de inovação da governança pública, que requer a adoção de novas estratégias de mobilização da sociedade civil e ocupação de novos espaços vinculados ao processo de tomada de decisão. As dificuldades derivadas da articulação entre governança pública e participação social decorrem do processo histórico de conformação do Estado brasileiro e da apropriação da esfera pública pela sociedade civil, organizada ou não. Por fim, por se tratar de um processo plural, que se desenvolve de diferentes formas no território brasileiro, é importante buscar novos estudos e apropriações do que se produz em caráter teórico ou empírico nesse campo.

\section{REFERÊNCIAS}

ARATO, Andrew; COHEN, Jean L. Sociedade civil e teoria social. In: AVRITZER, Leonardo (Coord.). Sociedade civil e democratização. Belo Horizonte: Del Rey, 1994. p. 41-80.

AZAMBUJA, Darcy. Introdução à ciência política. 17. ed. São Paulo: Globo, 2005.

BIGONHA, Antonio Carlos Alpino; GOMES JÚNIOR, Luiz Moreira. Legalidade e legitimidade na ordem constitucional de 1988: o papel do cidadão. In: ANTERO, Samuel A.; SALGADO, Valéria A. B. (Org.). Democracia, direito e gestão pública: textos para a discussão. Brasília: IFCI: AECID: MPOG: Editora IABS, 2012. p. 47-76.

BOBBIO, Norberto. Estado, governo e sociedade: para uma teoria geral da política. Tradução de Marco Aurélio Nogueira. 14. ed. São Paulo: Paz e Terra, 2007.

BOBBIO, Norberto. Liberalismo e democracia. Tradução de Marco Aurélio Nogueira. São Paulo: Brasiliense, 2000.

BOISIER, Sérgio. Política econômica, organização social e desenvolvimento regional. HADDAD, Paulo Roberto (Org.). Economia regional: teorias e métodos de análise. Fortaleza: BNB: ETENE, 1989.

BOURDIEU, Pierre. Sociologia. Tradução de Paula Montero e Alicia Auzmendi. São Paulo: Atlas, 1983.

BRASIL. Ministério da Administração Federal e da Reforma do Estado - MARE. Plano Diretor da Reforma do Aparelho do Estado. Brasília: MARE, 1995. 86 p. 
BRESSER-PEREIRA, Luiz Carlos. Assalto ao Estado e ao mercado: neoliberalismo e teoria econômica. Estudos Avançados, São Paulo, v. 23, n. 66, p. 7-23, 2009.

BRESSER-PEREIRA, Luiz Carlos. A reforma do estado dos anos 90: lógica e mecanismos de controle. Revista Lua Nova, São Paulo, n. 45, p. 49-95, 1998. Disponível em: http://www.bresserpereira.org.br/ papers/1998/A_reforma_do_Estado_dos_anos_90.pdf. Acesso em: 18 abr. 2018

CANÇADO, Airton; TAVARES, Bruno; DALLABRIDA, Valdir Roque. Gestão social e governança territorial: interseções, especificidades teórico-práticas. Revista Gestão e Desenvolvimento Regional, Taubaté, SP, v. 9, n. 3, p. 313-53, set./dez. 2013.

CHIZZOTTI, Antonio. Pesquisa em ciências humanas e sociais. 10. ed. São Paulo: Cortez, 2009. 164 p.

DAGNINO, Evelina. Sociedade civil, participação e cidadania: de que estamos falando? In: MATO, Daniel (Coord.). Políticas de ciudadanía y sociedad civil en tiempos de globalización. Caracas: Universidad Central de Venezuela, 2004a. p. 95-110.

DAGNINO, Evelina. Construção democrática, neoliberalismo e participação: os dilemas da confluência perversa. Política \& Sociedade, Florianópolis, v. 3, n. 5, p. 139-64, out. 2004b.

DALLABRIDA, Valdir Roque; MARCHESAN, Jairo; ROSSETTO, Adriana Marques; FILIPPIM, Eliane Salete. Governança nos territórios ou governança territorial: distância entre concepções teóricas e a prática. Revista Grifos, Chapecó, SC, n. 40, p. 43-66, 2016.

DALABRIDA, Valdir Roque. Governança territorial e desenvolvimento: as experiências de descentralização político-administrativa no Brasil como exemplos de institucionalização de novas escalas territoriais de governança. In: Circuito de Debates Acadêmicos (CODE 2011), 1., 2011. Anais [...]. Brasília: IPEA, 2011.

DALABRIDA, Valdir Roque. Desenvolvimento e governança territorial: um ensaio sobre a necessidade da regulação no processo de gestão do desenvolvimento. REDES, Santa Cruz do Sul, RS, v. 15, n. 3, p. 16586, set./dez. 2010.

DALABRIDA, Valdir Roque. A gestão territorial através do diálogo e da participação. Scripta Nova-Revista Electrónica de Geografía y Ciencias Sociales, Barcelona, v. 11, n. 245 (20), ago. 2007.

DALLABRIDA, Valdir Roque; BECKER, Dinizar Ferminiano. Governança territorial: um primeiro passo na construção de uma proposta teórico-metodológica. Desenvolvimento em Questão, ljuí, RS, ano 1, n. 2, p. 73-97, jul./dez. 2003.

DESLANDES, Suely Ferreira. O projeto de pesquisa como exercício científico e artesanato intelectual. In: MINAYO, Maria Cecília de Souza (Org.); DESLANDES, Suely Ferreira; GOMES, Romeu. Pesquisa social: teoria, método e criatividade. 26. ed. Petrópolis, RJ: Vozes, 2007. p. 31-60.

DIAS, Taisa; CARIO, Antonio Ferraz. Governança pública: ensaiando uma concepção. Contabilidade, Gestão e Governança, Brasília, v. 17, n. 3, p. 89-108, set./dez. 2014.

DURÁN, Francisco Entrena; LANNOO, Steven. El capital social en los territorios rurales y urbanos: perspectivas teóricas y evidencias empíricas. In: GEHLEN, Ivaldo; RIELLA, Alberto (Ed.). Território e sociedade: perspectivas teórico-metodológicas e evidências empíricas. Porto Alegre: Tomo Editorial, 2014. 320 p.

FAVARETO, Arilson; SCHRODER, Mônica. Do território como "ator" ao território como "campo": uma análise da introdução da abordagem territorial na política de desenvolvimento rural no Brasil. In: CONGRESSO 
DA SOCIEDADE BRASILEIRA DE ECONOMIA, ADMINISTRAÇÃO E SOCIOLOGIA RURAL, 45., Londrina, PR. Anais [...]. Londrina: UEL, 2007. p. 1-21.

FAVARETO, Arilson. As políticas de desenvolvimento territorial rural no Brasil em perspectiva: uma década experimentada. Desenvolvimento em Debate, Rio de Janeiro, v. 1, n. 2, p. 47-63, jan./ago. 2010.

FERRAREZI, Elisabete; OLIVEIRA, Clarice Gomes de. Reflexões sobre a emergência da participação social na agenda das políticas públicas: desafios à forma de organização burocrática do Estado. In: ANTERO, Samuel A.; SALGADO, Valéria A. B. (Org.). Participação social: textos para discussão. Brasília: IFCI: AECID: MPOG: Editora IABS, 2013. p. 117-40.

FUINI, Lucas Labigalini. Os Arranjos Produtivos Locais (APLs): uma breve explanação sobre o tema. GeoTextos, Salvador, BA, v. 9, n. 2, p. 57-83, dez. 2013.

GOHN, Maria da Glória. Movimentos sociais na contemporaneidade. Revista Brasileira de Educação, Rio de Janeiro, v. 16, n. 47, p. 333-61, maio/ago. 2011.

GOHN, Maria da Glória. O protagonismo da sociedade civil: movimentos sociais, ONGs e redes solidárias. 2. ed. São Paulo: Cortez, 2008.

GOMES, Romeu. Análise e interpretação de dados de pesquisa qualitativa. In: MINAYO, Maria Cecília de Souza (Org.); DESLANDES, Suely Ferreira; GOMES, Romeu. Pesquisa social: teoria, método e criatividade. 26. ed. Petrópolis, RJ: Vozes, 2007. p. 79-112.

GUTIERREZ, G. L.; ALMEIDA, M. A. B. Teoria da Ação Comunicativa (Habermas): estrutura, fundamentos e implicações do modelo. Veritas, Porto Alegre, v. 58, n. 1, p. 151-173, jan./abr. 2013.

HABERMAS, Jürgen. Historia y crítica de la opinión pública: la transformación estructural de la vida pública. 2. ed. Barcelona: Editorial Gustavo Gilli, 1981.

KRITSCH, Raquel. Estado e sociedade civil na teoria política: alguns paradigmas, muitas trajetórias. Política \& Sociedade, Florianópolis, v. 13, n. 18, p. 255-67, set./dez. 2014.

LINS, Hoyêdo Nunes. Regulação local: problemática e ensaio de observação. Ensaios FEE. Porto Alegre, v. 27, n. 1, p. 153-72, maio 2006.

LIMA, Ivaldo Gonçalves de. A governança territorial no rastro das redes políticas. In: CONGRESSO BRASILEIRO DE GEOGRAFIA POLIITICA, GEOPOLÍTICA E GESTÃO DO TERRITÓRIO, 1. Anais [...]. Porto Alegre: Editora Leitura 1, Rio de Janeiro: REBRAGEO, 2014. p. 1232-46.

MARTINS, Paulo Henrique. O dom como fundamento de uma cultura democrática e associativa. In: PORTUGAL, Sílvia. MARTINS, Paulo Henrique (Org.). Cidadania, políticas públicas e redes sociais. São Paulo: Annablume; Coimbra: Imprensa da Universidade de Coimbra, 2011. p. 13-27.

MINAYO, Maria Cecília de Souza. O desafio da pesquisa social. In: MINAYO, Maria Cecília de Souza (Org.); DESLANDES, Suely Ferreira; GOMES, Romeu. Pesquisa social: teoria, método e criatividade. 26. ed. Petrópolis, RJ: Vozes, 2007. p. 9-30.

NEVES, Fernando; ALLEDI FILHO, Cid; QUELHAS, Osvaldo; BONINA, Noemi; VIEIRA, Júlio; MARQUES, Vânia. Governança Pública: uma análise conceitual e comparativa. Revista Espacios, Venezuela, v. 38, n. 07, p. 6-29, 2017.

OBSERVATÓRIO DE POLÍTICAS PÚBLICAS PARA A AGRICULTURA (OPPA). Desenvolvimento territorial: articulação de políticas públicas e atores sociais. Rio de Janeiro: IICA-OPPA/CPDA/UFRJ, 2007. 
O'DONNEL, Guillermo. Estado, democratización y ciudadanía. In: CHUDNOVOSKY, Mariana. (Comp.). Capacidades estatales. Diez textos fundamentales. Argentina: CAF, 2015.

OLIVEIRA, Gilson Batista de. Uma discussão sobre o conceito de desenvolvimento. Revista FAE, Curitiba, v. 5, n. 2, p. 37-48, maio/ago. 2002.

PAES DE PAULA, Ana Paula. Por uma nova gestão pública: limites e potencialidades da experiência contemporânea. Rio de Janeiro: Editora FGV, 2005.

PIRES, Roberto Rocha Coelho; GOMIDE, Alexandre de Ávila. Governança e capacidades estatais: uma análise comparativa dos programas federais. Revista de Sociologia Política, Curitiba, v. 24, n. 58, p. 131-43, jun. 2016.

PIRES, Elson L. S.; FUINI, Lucas L.; MANCINI, Rodrigo F.; PICCOLI NETO, Danilo. Governança territorial: conceito, fatos e modalidade. Rio Claro, SP: UNESP-ICGE, 2011. 192 p.

QUEIROZ NETO, Exzovildres; RIBEIRO, Karoline; VARGAS, Luciane. O xadrez da organização do espaço: o jogo do(s) plano(s) no território do município. Teoria e Evidência Econômica, Passo Fundo, RS, ano 22, n. 46, p. 37-53, jan./jun. 2016.

RAFFESTIN, Claude. Por uma geografia do poder. São Paulo: Ática, 1993.

ROCHA, Eliane. A constituição cidadã e a institucionalização dos espaços de participação social: avanços e desafios. VAZ, Flávio Tonelli; MUSSE, Juliano Sander; SANTOS, Rodolfo Fonseca dos (Coord.). 20 anos da Constituição Cidadã: avaliação e desafios da Seguridade Social. Brasília: ANFIP, 2008. P 131-48. Disponível em: http://www2.anfip.org.br/publicacoes/livros/includes/livros/arqs-pdfs/ Livro_da_20_anos_Constituicao72dpi.pdf Acesso em: 7 jul.2020.

SECCHI, Leonardo. Políticas públicas: conceitos, esquemas de análise, casos práticos. 2. ed. São Paulo: Cengage Learning, 2015. 168 p.

SECCHI, Leonardo. Modelos organizacionais e reformas da administração pública. Revista da Administração Pública, Rio de Janeiro, v. 43, n. 2, p. 347-69, mar./abr. 2009.

SEPÚLVEDA, Sergio; ECHEVERRI, Rafael; RODRIGUEZ, Adrian. El enfoque territorial del desarrollo rural: retos para la reducción de la pobreza. Documento apresentado no Seminario Reducción de la Pobreza Rural en Centroamérica: fortalecimiento de servicios técnicos, empresariales y financieros, CATIE, Turrialba, Costa Rica, 2005.

SIONG, Neo Boon; CHEN, Geraldine. Dynamic governance: embedding culture, capabilities and change in Singapore. Singapura: World Scientific, 2007.

SOUZA, Celina; CARVALHO, Inaiá. Reforma do Estado, descentralização e desigualdades. Lua Nova: Revista de Cultura e Política, São Paulo, n. 48, dez. 1999. Disponível em: http://www.scielo. br/scielo.php?script=sci_arttext\&pid=S0102-64451999000300011. Acesso em: 18 abr. 2018.

ZANELLA, Andreia Vieira. Escolarização formal e cidadania: possíveis relações, relações possíveis? In: SILVERA, Andréa F.; GEWEHR, Catarina; BONIN, Luiz Fernando R.; BULGACOV, Yara L. M. Cidadania e participação social. Rio de Janeiro: Centro Edelstein de Pesquisas Sociais, 2008. p. 84-91. 


\section{Sobre os autores:}

Alessandra de Sant'Anna: Doutoranda no Instituto de Pesquisa em Planejamento Urbano e Regional da Universidade Federal do Rio de Janeiro (UFRJ). Mestra em Políticas Públicas e Desenvolvimento pela Universidade Federal da Integração Latino-Americana (PPGPPD/Unila). E-mail: alessandradesantanna@gmail.com, Orcid: https://orcid.org/0000-0003-4762-7022

Exzovildres Queiroz Neto: Doutor em Engenharia Agrícola, Planejamento e Desenvolvimento Rural Sustentável pela Universidade Estadual de Campinas (Feagri/Unicamp). Professor do Programa de Pós-Graduação em Políticas Públicas e Desenvolvimento da Universidade Federal da Integração Latino-Americana (Unila). E-mail: queiroz.neto@unila.edu.br, Orcid: http://orcid.org/0000-0002-7190-2250

Jamur Johnas Marchi: Doutor em Administração pela Universidade Federal de Santa Catarina (PPGA/UFSC), professor do Programa de Pós-Graduação em Políticas Públicas e Desenvolvimento da Universidade Federal da Integração Latino-Americana (Unila).E-mail: jamur.marchi@unila.edu.br, Orcid: http://orcid.org/0000-0001-6620-5699 
